\title{
I.3. Visualização de signos: entre 0 design e a semiótica
}

Os aspectos fundamentais da semiótica de Peirce, conforme vimos, dependem dos princípios que orientaram a construção de sua teoria do signo. Se um signo pode ser entendido como uma relação irredutível, então as classificações de signos podem ser descritas como "relações entre relações". Conforme salientamos na Seção I.1.3, estes complexos de relações tornam-se cada vez mais intrincados quanto maior o número de aspectos tricotômicos que consideramos. Isso diz respeito não só à quantidade de tricotomias envolvidas em uma classificação, mas também às relações entre classes, como aquelas expostas na Tabela 1.

Contudo, se levarmos a sério os argumentos de Peirce quanto às vantagens do raciocínio diagramático para a compreensão de problemas que podem ser expressos em termos de relações, devemos esperar que o desenvolvimento de diagramas auxilie no entendimento de sua teoria do signo. Em Farias e Queiroz (2000a), ao buscar esclarecer o modo como chegamos ao projeto que deu origem ao diagrama 10cubes (ver Seção II.3.4), propusemos um esboço de metodologia para um tipo de investigação, eminentemente visual, de certos aspectos da teoria do signo de Peirce.

Esta proposta tornou-se o embrião de um programa de pesquisa que chamamos visualização de signos. Apresentamos esse programa de pesquisa, que em outras ocasiões (FARIAS, 2001A, 2002; FARIAS; QUEIROZ, 2000a, 2000d, 2001) chamamos de sign design, discutimos sua metodologia e introduzimos alguns exemplos de aplicação.

\section{I.3.1. 0 que é visualização de signos}

Visualização de signos é um programa de pesquisa envolvendo novas estratégias de modelagem e implementação de novas formas de visualização da teoria do signo de Peirce. Trata-se de uma abordagem sistemática da teoria do signo de Peirce. Seu objetivo é a construção de modelos visuais de estruturas 
e processos semióticos, estabelecendo conexões entre a semiótica peirceana e os campos do design e do raciocínio diagramático (ou diagrammatic reasoning; CHANDRASEKARAN et al. 1995; BLACKWELL 2001). Do design, e em particular do design gráfico, ela extrai uma metodologia. Em comum com o campo de investigação conhecido como "raciocínio diagramático", ela supõe que diagramas são valiosas estruturas e objetos, como artefatos para solução de problemas específicos e, uma forma geral, como auxiliares na organização das atividades cognitivas (cf. CHANDRASEKARAN et al. 1995: xv-xxvii).

Já apresentamos (FARIAS 2001A, 2001B, 2002; FARIAS; QUEIROZ 2000a, 2000b, 2000c, 2000d, 2001, 2004) resultados de duas pesquisas que envolviam a aplicação deste tipo de abordagem no campo das classificações sígnicas de Peirce. Afirmamos (FARIAS; QUEIROZ 2000a) que a estratégia adotada nestas pesquisas pode ser generalizada como um método de investigação no campo da semiótica. Como método, ele aproxima-se do que Zellweger (1982: 17) chama de man-sign engineering. Zellweger destaca a necessidade de exploração de uma área aplicada e experimental da semiótica, dedicada à "criação de signos" com base em "esforços coletivos altamente especializados para compreender e melhorar nossas ferramentas mentais" (ZELLWEGER 1982, p. 17-18). Segundo Zellweger, o principal desafio desta área é "projetar signos" capazes de estabelecer, através da "iconicidade visual" de suas "estruturas de superfície", um isomorfismo entre "a rede de relações existentes em uma sociedade de signos e a rede correspondente que existe na estrutura profunda daquilo que está sendo simbolizado" (ZELLWEGER 1982, p. 19-20). Zellweger nomeia este isomorfismo de "iconicidade relacional". Seu plano se divide em duas partes: (i) identificação das estruturas abstratas que deverão ser simbolizadas; e (ii) invenção e desenvolvimento de um sistema de signos que incorpore e revele, de forma visual, as relações presentes nestas estruturas. Em diversos artigos, Zellweger demonstrou seus resultados no desenvolvimento de novas notações em lógica (ZELLWEGER 1982, 1991, 1992, 1997a, 1997b).

O desenvolvimento de diagramas mais efetivos, a partir da aplicação de estratégias metodológicas do design, faz parte de um conjunto de pressupostos gerais aceitos pelo design. A estes pressupostos, a visualização de signos associa a hipótese de que estas estratégias poderiam contribuir para a capacidade dos diagramas de "revelar verdades inesperadas" (CP 2.279, Seção I.2.1). Outro objetivo da visualização de signos é fornecer 
instrumentos para investigações semióticas (inclusive na área do design) a partir da compreensão daquilo que podemos chamar de "design da semiótica".

A Seção I.3.2 apresenta uma metodologia para visualização de signos.

\section{I.3.2. Uma proposta de metodologia para visualização de signos}

A metodologia proposta para visualização de signos consiste em três fases inter-relacionadas: (i) conceitualização, (ii) desenvolvimento e (iii) experimentação. Metodologias de projeto na área de design baseadas em três fases são bastante comuns. Para Villas-Boas (1999: 41), elas podem ser resumidas no trinômio "problematização, concepção e especificação". Alguns exemplos deste tipo de metodologia são a estrutura de desenvolvimento baseada em três passos, "meta-planejamento, planejamento e design", proposta por Owen (1998), o "Método de Desdobramento em 3 Etapas" (MD3E) formalizado por Santos $(2000)^{28}$ e o processo recursivo "descoberta $\rightarrow$ design $\rightarrow$ uso $\rightarrow$ descoberta $\rightarrow$..." descrito por Cato (2001: 9-17).

As três fases da metodologia proposta para visualização de signos são:

(i) Fase de conceitualização: são exploradas as bases teóricas e conceituais para o design de estruturas e processos semióticos. A fase de conceitualização dos modelos (apresentados nas Seções II.3.4 e II.3.5) envolveu uma investigação do modelo de signo, e sua descrição, em diferentes tipos, através das classificações sígnicas. Os primeiros trechos das Seções II.3.4 e II.3.5 são exemplos de descrição desta fase.

(ii) Fase de desenvolvimento: os resultados da fase de conceitualização são aplicados ao design de um novo modelo. Trata-se de uma fase prática, fundamentada na tradução visual dos elementos teóricos sistematizados na fase anterior. Esta fase inclui desde a geração de alternativas para a interface até a implementação dos diagramas.

(iii) Fase de experimentação: em que as informações visuais proporcionadas pelo modelo construído na fase de desenvolvimento devem ser testadas. Os resultados desta fase devem ser comparados e avaliados à luz da fase conceitualização. Os últimos trechos das Seções 2.3.4 e 2.3.5 exibem alguns resultados desta fase. Em Farias e Queiroz (2000a), afirmamos que a ênfase na
Santos (2000) propõe uma estrutura baseada em três etapas que se desdobram em três, da seguinte forma:

1. Pré-concepção

1.1. Definição do problema

1.2. Especificação do produto

1.3. Especificação do projeto

2. Concepção

2.1. Geração de alternativas

2.2. Seleção das alternativas

2.3. Definição e justificativa

3. Pós-concepcão

3.1. Detalhamento dos subsistemas

3.2. Especificação de componentes

3.3. Especificação da produção, venda e pós-venda. 
experimentação constitui um traço distintivo desta estratégia em relação à postura de outros especialistas, cujos modelos parecem ser objetos estanques e não ferramentas dinâmicas para investigação.

Em Farias e Queiroz (2000b) chamamos atenção para o fato de que os modelos desenvolvidos através desta metodologia, mais do que ilustrações de aspectos de uma teoria, deveriam funcionar como ferramentas visuais de investigação. Isto significa que, se um modelo é suficientemente bem desenvolvido, devemos ser capazes de postular e testar visualmente certas hipóteses em relação aos processos e estruturas sígnicas especificadas na fase conceitual (fase i). Quanto ao processo como um todo, cremos que uma melhor estratégia de design na fase de desenvolvimento (fase ii) deve levar a um modelo mais produtivo na fase de experimentação (fase iii). De modo complementar, fraquezas ou inconsistências na fase de experimentação (fase iii) deveriam levar a uma reconsideração das premissas assumidas na fase de conceitualização (fase i) e das estratégias utilizadas na fase de desenvolvimento (fase ii).

\section{I.3.3. Aplicações para a visualização de signos}

A estratégia descrita nas seções anteriores foi desenvolvida a partir da suposição de que certos aspectos da teoria peirceana poderiam ser melhor compreendidos se investigados visualmente. Os dois diagramas dinâmicos apresentados nas Seções 2.3.4 e 2.3.5 deste livro são exemplos de como esta estratégia foi aplicada, com sucesso, no campo das classificações sígnicas de Peirce. A definição de uma metodologia para visualização de signos tem, como objetivos, exibir o processo de criação destes diagramas, e incentivar o desenvolvimento de novos modelos.

A estratégia de aproximar o estudo da semiótica à prática do design, deve ser de especial interesse para as áreas do design e da comunicação. Há consenso sobre a importância do ensino da semiótica nestas áreas. A semiótica de Peirce interessa tanto à análise quanto ao desenvolvimento de projetos. Ao mesmo tempo, uma abordagem estritamente teórica desta disciplina torna-a, por vezes, tão dissociada da prática do design que sua relevância parece questionável. O que chamamos de "semiótica aplicada" é um tópico geralmente tratado através de uma abordagem baseada em leituras e desenvolvimentos descritivos, classificatórios ou analíticos (ver, por exemplo, Im 1998: 176).

A metodologia apresentada na seção anterior pode ser utilizada com propósitos investigativos, orientando estudantes e 
pesquisadores no desenvolvimento de trabalhos práticos que requerem um estudo cuidadoso da teoria do signo de Peirce. O resultado deste esforço é um conjunto de ferramentas que, por sua vez, é utilizado em um curso de design para explicar tópicos complexos da teoria do signo de Peirce. Tais ferramentas, enquanto dispositivos experimentais, são de especial interesse em vista da afinidade dos estudantes de design com o que chamamos de raciocínio diagramático.

Em resumo, visualização de signos parece ter um duplo interesse para as áreas do design e da comunicação: por um lado, sua metodologia sugere uma forma prática e visual de investigação, que poderíamos chamar de "semiótica do design", ou "design aplicado à semiótica". Por outro, as ferramentas construídas por meio desta metodologia devem ser capazes de auxiliar o ensino da semiótica em cursos de design, com especial interesse para o desenvolvimento de uma semiótica do design baseada na teoria de Peirce. 
